\title{
The Study of Multi Machine Equivalent Model Of Wind Farm Based On The Wind Speed
}

\author{
Qing Liu ${ }^{1, \text { a }}$ \\ ${ }^{1}$ School of North China Electric Power University, 071000, China. \\ a756064199@qq.com
}

\begin{abstract}
Keywords: Wind Farm Equivalent Method, Clustering Algorithm, Equivalent Modeling, PSCAD Time-domain Simulation.
\end{abstract}

\begin{abstract}
With the rapid development of wind power technology, the size and number of grid-connected wind farms increase rapidly. Equivalent modeling of wind farms is the basis of the research on grid operating characteristics after wind power is connected to the grid. Long-distance transmission of large-scale wind power has become an inevitable trend, it seems that it is meaningful to study the equivalent model of wind farm. This paper build a multi machine equivalent model of wind farm

By using the power system time domain simulation software-PSCAD/EMTDC. After debugging the model and running simulation, it build a specific equivalent model of wind farm and the results after the simulation of equivalent model.
\end{abstract}

\section{Introduction}

Multi machine equivalent method clusters wind farm in the wind into partitions, the thought is from homology equivalence method of power system dynamic equivalence method. This kind of research defines the clustering index of wind farm, then it regards every kind of wind turbines as equivalence to a wind machine considering the differences of parameter values. Many machine equivalent method will come up with different ways when the clustering index is different. [1] Equivalent model of wind farm by using the equivalent wind speed, but wind speed can't become the only measure to reflects the operating point of the wind turbines, which makes this method is not accurate. [2] In wind power units with similar operating point as units based on principle and taking the speed of the wind turbines for the fleet when the fault classification index can well reflect the practical operation of wind turbines. It can also more accurately reflect the dynamic characteristics of the constant speed wind farm crew and branch. So this method is suitable for analysis of large capacity wind effects on power system. [3] Using state variables in the process of wind turbine simulation matrix as a clustering index and K Means clustering algorithm has high precision. On the analysis of large scale doubly-fed type wind power impact on power grid can achieve the goal of reduced order. So it can be used to describe the actual running condition of the wind farm.

\section{Wind machine more equivalence method based on clustering method}

\subsection{K-Means clustering algorithm}

Clustering analysis is a static data analysis method, is often used in machine learning, pattern recognition, data mining and other fields. It refers to the set of physical or abstract process of grouped into multiple classes, Its purpose is to put a large amount of sample collection is divided into several classes, making maximum similarity between samples of each class, rather than the similar maximum difference of the sample. [4]

The basic idea is the initial clustering center randomly given $\mathrm{K}$, in accordance with the principle of the adjacent sort to sample points assigned to each class. And then recalculate the center of the classes, identified as new clustering center. Iteration until the clustering center's mobile distance is less than a given value. 
This paper put all wind turbines fleet classification index and classification number $\mathrm{K}$ into the $\mathrm{K}$ - Means algorithm to get a fleet of classification index $\mathrm{K}$ group. Each classification index corresponds to a typhoon electric unit. Finally it can get the fan group of wind farm based on the results.

\subsection{Wind farm equivalent based on the wind speed}

A wind farm in a 16 sets under the condition of the wind generator for wind speed conditions such as table1:

Table1: every wind turbines wind speed of wind farm

\begin{tabular}{cc||cc}
\hline number & Wind speed(m/s) & number & wind speed(m/s) \\
\hline 1 & 9.5 & 9 & 9.4 \\
2 & 12.6 & 10 & 13.4 \\
3 & 13.2 & 11 & 13.7 \\
4 & 14.2 & 12 & 20.8 \\
5 & 11.8 & 13 & 9.3 \\
6 & 12 & 14 & 13 \\
7 & 14.5 & 15 & 14.1 \\
8 & 15 & 16 & 20.9 \\
\hline
\end{tabular}

In wind speed for clustering index, using MATLAB to 3 - Means cluster computing, all the wind turbines clustering results such as table 2:

Table 2: result of clustering index based on wind speed wind turbines clustering

\begin{tabular}{cc}
$\begin{array}{c}\text { equivalent wind } \\
\text { turbines }\end{array}$ & results \\
\hline 1 & $1,9,13$ \\
2 & $2,3,4,5,6,7,8,10,11,14,15$ \\
3 & 12,16 \\
\hline
\end{tabular}

\subsection{Parameter calculation of Equivalent units}

A wind farm is composed of $\mathrm{M}$ the same type of wind turbine, using fleet classification index and clustering algorithm of wind turbines into $\mathrm{K}$ group, and each fleet merged into an equivalent wind turbines. All the parts of the equivalent wind turbine parameters (value) famous formula, respectively:

(1) generator parameters:

$$
\left\{\begin{array}{l}
S_{G_{-} e q}=\sum_{i=1}^{m} S_{i}, P_{G_{-} e q}=\sum_{i=1}^{m} P_{i}, x_{m_{-} e q}=\frac{x_{m}}{m} \\
x_{1_{-} e q}=\frac{x_{1}}{m}, x_{2_{-} e q}=\frac{x_{2}}{m}, r_{1_{-} e q}=\frac{r_{1}}{m}, r_{2_{-} e q}=\frac{r_{2}}{m}
\end{array}\right.
$$

In the formula, before $\mathrm{m}$ is equivalent with the group of wind turbines sets; The subscript eq said after the equivalent; S, said capacity, active power P; For generator excitation reactance, generator stator reactance, resistance respectively

(2) the wind speed and fan parameters

$$
v_{e q}=\frac{1}{m} \sum_{i=1}^{m} v_{i}, H_{e q}=\sum_{i=1}^{m} H_{i}, \quad D_{e q}=\sum_{i=1}^{m} D_{i}
$$

In the formula, $\mathrm{V}$ as the wind speed, for generator rotor time constant, $\mathrm{H} \mathrm{D}$ for generator shafting damping coefficient. Example of a wind farm 16 sets the wind generator is the original parameters 
such as table 3:

Table 3: original parameters of Wind turbines

\begin{tabular}{ccc} 
& Rated power/kW & 750 \\
The Rated voltage $/ \mathrm{V}$ & 690 \\
Rated frequency/Hz & 50 \\
fan parameters & $r_{1}(\mathrm{pu})$ & 0.0103 \\
& $r_{2}(\mathrm{pu})$ & 0.01718 \\
$X_{m}(\mathrm{pu})$ & 7.8 \\
$X_{1}(\mathrm{pu})$ & 0.11 \\
& $X_{2}(\mathrm{pu})$ & 0.124 \\
\hline Wind turbine & $H / \mathrm{s}$ & 2.5 \\
parameters & $D(\mathrm{pu})$ & 0 \\
\hline
\end{tabular}

Ignore the generator stator resistance, Equivalent to wind the clustering index of the machine after the equivalent unit parameters such as table 4:

Table 4: Equivalent to wind the clustering index of the machine after the equivalent unit parameters

\begin{tabular}{|c|c|c|c|c|c|c|c|}
\hline & $P_{G_{-} e q}$ & $X_{m e q}$ & $X_{1}$ eq & $X_{2}$ eq & $V_{e q}$ & $H_{e q}$ & $D_{e q}$ \\
\hline$W T_{\text {eq_1 }}$ & $2.25 \mathrm{MW}$ & 2.60 & 0.037 & 0.041 & $9.40 \mathrm{~m} / \mathrm{s}$ & $7.50 \mathrm{~s}$ & 0 \\
\hline$W T_{\text {eq_2 }}$ & $8.25 \mathrm{MW}$ & 0.71 & 0.010 & 0.011 & $13.41 \mathrm{~m} / \mathrm{s}$ & $27.5 \mathrm{~s}$ & 0 \\
\hline$W T_{\text {eq_3 }}$ & $1.50 \mathrm{MW}$ & 3.90 & 0.055 & 0.062 & $20.85 \mathrm{~m} / \mathrm{s}$ & $5.00 \mathrm{~s}$ & 0 \\
\hline
\end{tabular}

\section{Multi Machine Equivalent Model}

Multi machine equivalent model using the method of clustering will have similar characteristics of wind turbine wind farm equivalent for the wind generator sets (3), the unit after mechanical and electrical parameters according to the equivalent input parameters. The input of wind speed is equivalent wind speed, Equivalent model as shown in figure1:

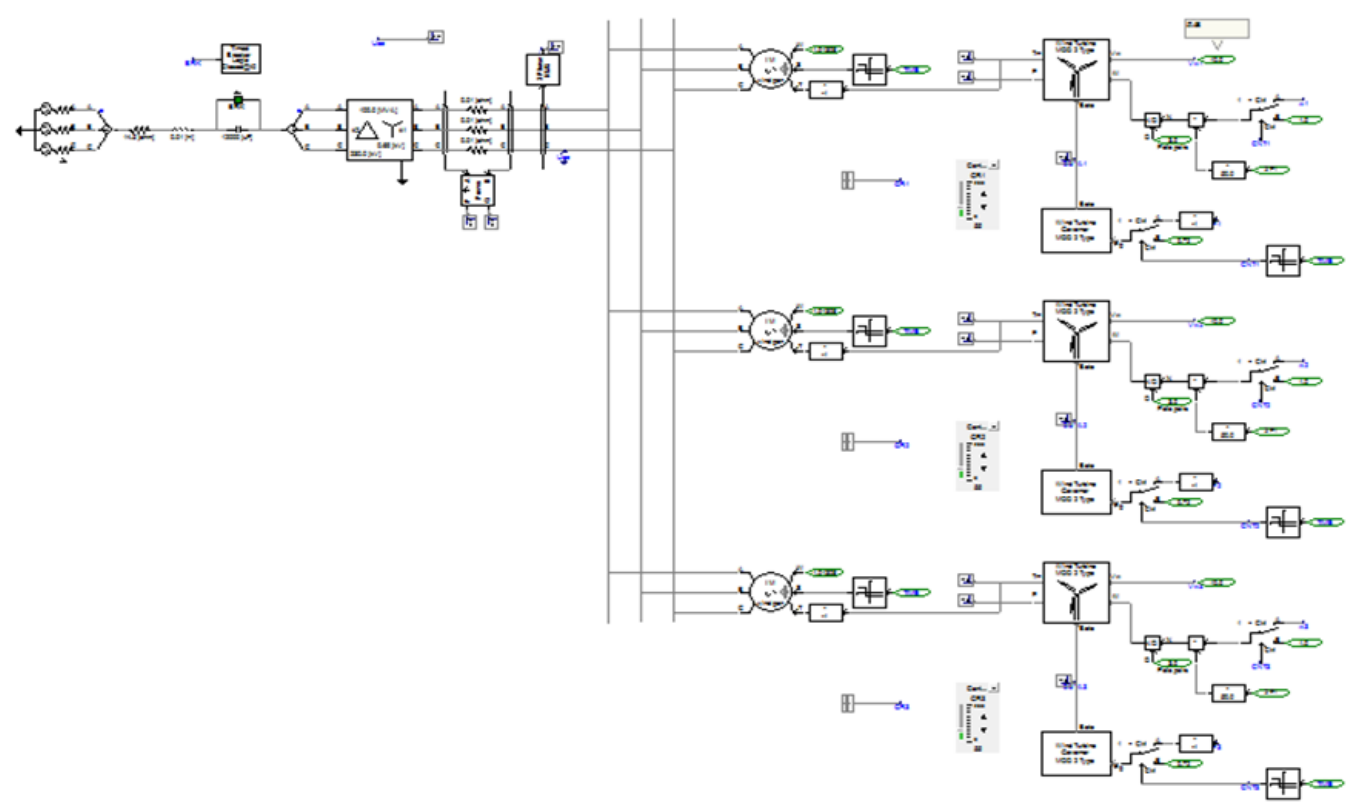

Figure1: Wind farm machine equivalent model 


\section{Summary}

This wind farm machine equivalent model is the use of $\mathrm{K}$ - Means clustering algorithm of MATLAB. The Indicators of the model is wind speed. We can use this model to go ahead with study of wind farm. It has strong practical significance.

\section{References}

[1] Fu Rong Xie Jun, bao yun wang. Wind speed fluctuation under the doubly-fed generator wind dynamic equivalence [J]. Power system protection and control, 2012,p.1-6.

[2] M enhancement, Su Xunwen, Yang Ji, wang yi, ng to. The more dynamic equivalent model of wind farms machine characterization method [J]. Journal of electrotechnics, 2010-12,p.162-169

[3] Shu-yong Chen, wang cong, ShenHong Gao Ning super, zhu Lin, LanHua. Wind dynamic equivalence based on clustering algorithm [J]. Proceedings of the csee, 2012, p.11-19 + 24 .

[4]Helen, Wu Ling, Cai Yi. Clustering algorithm in data mining review [J]. Computer application research, 2007-01,p.10 to 13 